\title{
Reduction of Skin pH during Treatment for Palmoplantar Hyperhidrosis: A Conjecture on the Role of pH-Regulated Water Channel, i.e. Aquaporin
}

\author{
Kyoko Nakahigashi Takashi Nomura Yoshiki Miyachi \\ Kenji Kabashima \\ Department of Dermatology, Kyoto University Graduate School of Medicine, Kyoto, Japan
}

\section{Key Words}

Skin $\mathrm{pH}$ - Palmoplantar hyperhidrosis · Water iontophoresis · Topical aluminum chloride

\begin{abstract}
Primary palmoplantar hyperhidrosis (PPH) is a disorder that involves excessive sweating on the palms and soles. Although the pathophysiology of PPH remains unknown, some treatments, including topical aluminum chloride (AC) and tap water iontophoresis (TWI), are effective at suppressing the perspiration. Herein, we report the kinetics of the skin $\mathrm{pH}$ of two cases of PPH treated with AC and TWI. We found that the skin pH decreased in accordance with the reduction in sweating. This finding indicates that the reduction in sweating may be attributed to the reduction of skin $\mathrm{pH}$ in $\mathrm{AC}$ and TWI. Whether or not the $\mathrm{pH}$-regulated function of aquaporin can explain this finding remains unknown.
\end{abstract}

\section{Introduction}

Primary focal hyperhidrosis is a disorder that involves excessive, bilateral, and relatively symmetric sweating in the axillae, palms, soles, or craniofacial region. The condition, particularly in palmoplantar hyperhidrosis, can result in psychological and physical impairment and can also result in social stigmatization. At present, the pathophysiology of primary palmoplantar hyperhidrosis (PPH) remains unknown. As such, the therapy is not based on the cause. Treatment options include topical aluminum chloride (AC), tap water iontophoresis (TWI), botulinum toxin A, oral anticholinergics, and endoscopic sympathec-

Kenji Kabashima, MD, PhD

Department of Dermatology

Kyoto University Graduate School of Medicine

54, Kawahara-cho, Shogoin, Sakyo-ku, Kyoto 606-8507 (Japan)

E-Mail kaba@kuhp.kyoto-u.ac.jp 
tomy. Among them, TWI and AC are routinely performed and are often effective $[1,2]$. The accumulation of $\mathrm{H}^{+}$within the sweat ducts as a result of the anodal current is suggested to be the mechanism of the TWI-induced inhibition of sweating [3]. In contrast, topical AC is considered to induce an aluminum salt blockage of the distal acrosyringium and structural changes of the eccrine glands [4]. The effect of AC on skin $\mathrm{pH}$ has not yet been addressed.

Aquaporin $(\mathrm{AQP})$ is a water-transporting protein that has a variety of physiological functions in the skin [5-7]. AQP-5 is expressed in mammalian sweat glands and has been reported to play a role in sweating in mice, rats, and horses. Although the role of AQP-5 remains unclear in humans $[8,9], \mathrm{AQP}$ members may regulate sweating by controlling the water transport. Of note, it has been suggested that the water permeability of AQP is regulated by $\mathrm{pH}[10]$. Therefore, we evaluated the skin $\mathrm{pH}$ before and after antihidrotic therapy, based on the hypothesis that the skin $\mathrm{pH}$ might be related to sweating.

\section{Case Presentation}

A 45-year-old woman (case 1) and a 27-year-old woman (case 2) suffered from PPH since childhood. Case 1 was initially treated by topical AC application. Three weeks later, she underwent weekly TWI with a direct current at $12 \mathrm{~mA}$ for $20 \mathrm{~min}$. The sweating was slightly reduced in 4 weeks and was markedly reduced in 8 weeks. Case 2 was treated with a daily application of $20 \%$ AC solution. The sweating was slightly reduced in 2 weeks and was markedly reduced in 4 weeks.

Skin surface $\mathrm{pH}$ was measured using a skin $\mathrm{pH}$ meter (D-51, Horiba, Ltd., Tokyo, Japan) according to the manufacturer's protocol. The design was validated in a pilot study. The experiment was performed in a room with a temperature of $24^{\circ} \mathrm{C}$ and humidity below $65 \%$. The patients were kept at rest and the measurement was conducted after the skin was slightly wiped with tissues. The mean $\mathrm{pH}$ values were calculated in four sites on both the palms and soles. Twelve healthy volunteers ( 7 males and 5 females, mean \pm SD age $33.6 \pm 5.5$ years, range 24-46) were also enrolled in the study.

The $\mathrm{pH}$ of patients with PPH before treatment tended to be high compared to that of healthy subjects (pH of healthy subjects, $5.23 \pm 0.22$; $\mathrm{pH}$ of PPH, 6.17 in case 1 and 6.65 in case 2). The comparison of $\mathrm{pH}$ before and after the antihidrotic therapy was analyzed by the paired test (fig. 1). In both cases, the skin $\mathrm{pH}$ was significantly decreased following the treatment and was accompanied by reduced sweating.

\section{Discussion}

The first-line therapy for PPH is the topical application of AC solution or TWI [1]. The widely accepted underlying mechanism of these treatments is the blockage of the distal acrosyringium and structural changes of the eccrine glands by AC salts as well as the impaired perspiration caused by $\mathrm{H}^{+}$movement into sweat ducts by TWI $[3,4]$. In this report, however, we observed a reduction in skin $\mathrm{pH}$ with both $\mathrm{AC}$ and TWI treatment. At present, it remains unclear if the reduction in skin $\mathrm{pH}$ after $\mathrm{AC}$ and TWI treatment is the cause or the result of decreased sweating. Our finding calls the role of the anatomical changes observed in AC-treated skin into question and focuses on the importance of reduced $\mathrm{pH}$ in the inhibition of sweating. A low $\mathrm{pH}$ condition has been shown to inhibit water transfer by AQP. As such, it is intriguing to examine the functions of AQP-5 before and after treatment for PPH. 
Nakahigashi et al.: Reduction of Skin pH during Treatment for Palmoplantar Hyperhidrosis

\section{Funding Sources}

This work was supported in part by Grants-in-Aid for Scientific Research from the Ministries of Education, Culture, Sports, Science and Technology, and Health, Labor and Welfare of Japan.

\section{Disclosure Statement}

The authors declare no conflict of interest.

\section{References}

1 Hornberger J, Grimes K, Naumann M, Glaser DA, Lowe NJ, Naver H, Ahn S, Stolman LP: Recognition, diagnosis, and treatment of primary focal hyperhidrosis. J Am Acad Dermatol 2004;51:274-286.

$>2$ Eisenach JH, Atkinson JL, Fealey RD: Hyperhidrosis: evolving therapies for a well-established phenomenon. Mayo Clin Proc 2005;80:657-666.

-3 Sato K, Timm DE, Sato F, Templeton EA, Meletiou DS, Toyomoto T, Soos G, Sato SK: Generation and transit pathway of $\mathrm{H}+$ is critical for inhibition of palmar sweating by iontophoresis in water. J Appl Physiol 1993;75:2258-2264.

-4 Yanagishita T, Tamada Y, Ohshima Y, Ito K, Akita Y, Watanabe D: Histological localization of aluminum in topical aluminum chloride treatment for palmar hyperhidrosis. J Dermatol Sci 2012;67:69-71.

-5 Hara-Chikuma M, Chikuma S, Sugiyama Y, Kabashima K, Verkman AS, Inoue S, Miyachi Y: Chemokinedependent $\mathrm{T}$ cell migration requires aquaporin-3-mediated hydrogen peroxide uptake. J Exp Med 2012;209:1743-1752.

-6 Hara-Chikuma M, Sugiyama Y, Kabashima K, Sohara E, Uchida S, Sasaki S, Inoue S, Miyachi Y: Involvement of aquaporin-7 in the cutaneous primary immune response through modulation of antigen uptake and migration in dendritic cells. FASEB J 2012;26:211-218.

-7 Nakahigashi K, Kabashima K, Ikoma, Verkman AS, Miyachi Y, Hara-Chikuma M: Upregulation of aquaporin-3 is involved in keratinocyte proliferation and epidermal hyperplasia. J Invest Dermatol 2011;131:865-873.

-8 Iizuka T, Suzuki T, Nakano K, Sueki H: Immunolocalization of aquaporin-5 in normal human skin and hypohidrotic skin diseases. J Dermatol 2012;39:344-349.

-9 Kabashima K, Shimauchi T, Kobayashi M, Fukamachi S, Kawakami C, Ogata M, Kabashima R, Mori T, Ota T, Fukushima S, Hara-Chikuma M, Tokura Y: Aberrant aquaporin 5 expression in the sweat gland in aquagenic wrinkling of the palms. J Am Acad Dermatol 2008;59:S28-S32.

10 Németh-Cahalan KL, Hall JE: pH and calcium regulate the water permeability of aquaporin 0. J Biol Chem 2000;275:6777-6782.

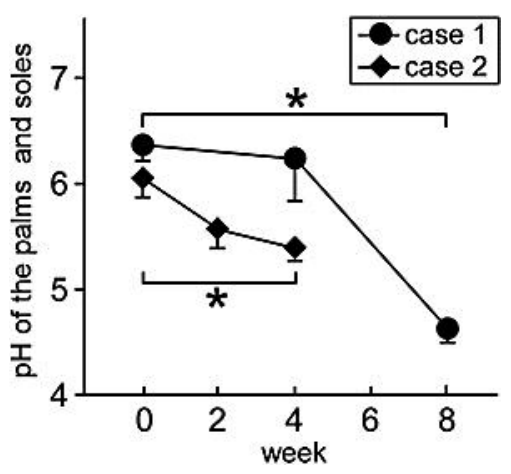

Fig. 1. Kinetics of skin pH in cases of PPH during treatment. Case 1 was treated by topical AC and TWI and case 2 was treated by topical AC. The mean $\mathrm{pH}$ values and standard deviations were calculated from the measurements of four sites on both the palms and soles. ${ }^{*} \mathrm{p}<0.05$ (paired t test). 